\title{
Racemization-free synthesis of dipeptide, amide and ester by oxalyl chloride and catalytic triphenylphosphine oxide
}

\author{
Ji-Wei Ren, ${ }^{\text {a,b }}$ Meng-Nan Tong, ${ }^{a}$ Yu-Fen Zhao, ${ }^{\text {a,b }}$ Feng Ni ${ }^{\text {a,b }}$ \\ ${ }^{a}$ Institute of Drug Discovery Technology, Ningbo University, Ningbo, Zhejiang, 315211, P. R. China. \\ ${ }^{\mathrm{b}}$ Qian Xuesen Collaborative Research Center of Astrochemistry and Space Life Sciences, Ningbo University, Ningbo, \\ Zhejiang, 315211, P. R. China.
}

\section{Supporting Information Placeholder}

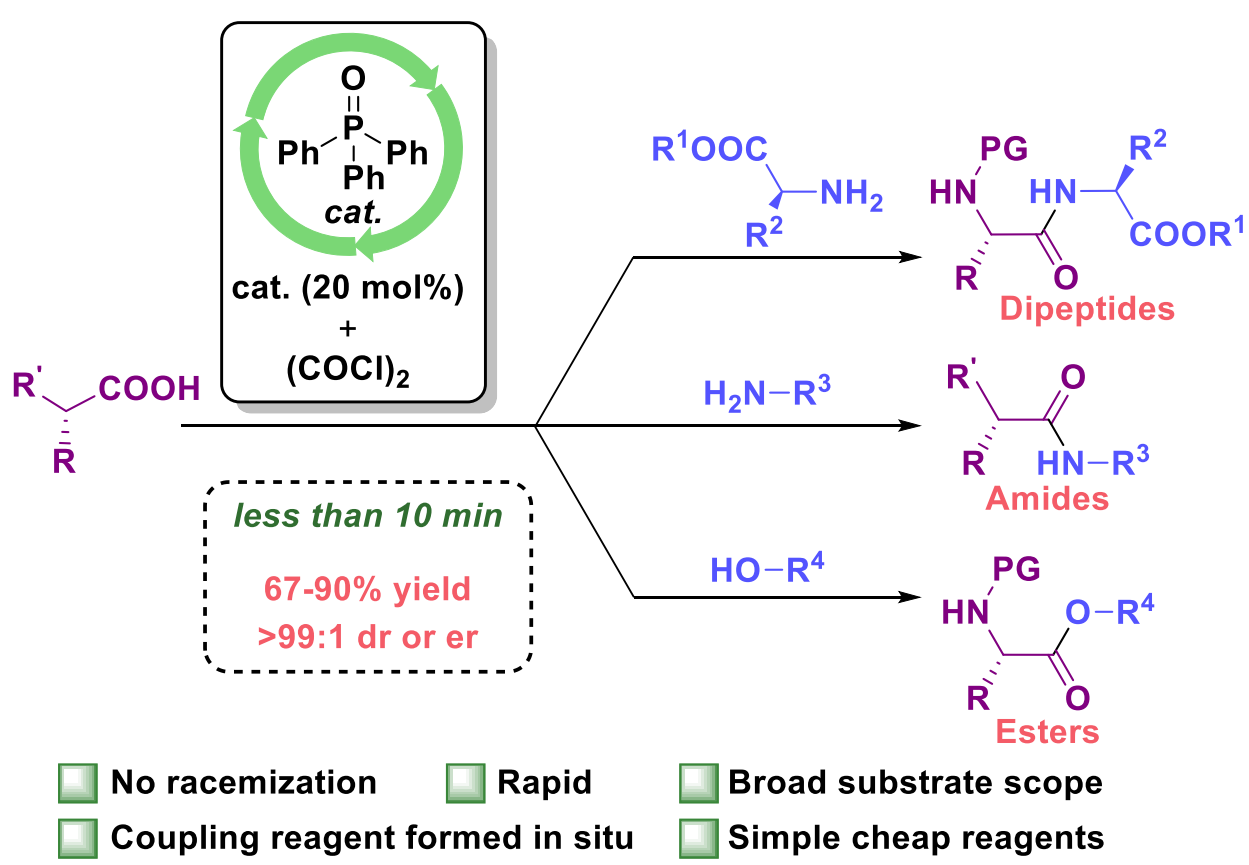

\footnotetext{
ABSTRACT: An efficient triphenylphosphine oxide $\left(\mathrm{Ph}_{3} \mathrm{PO}\right)$ catalyzed amidation and esterification reaction for rapid synthesis of a series of dipeptides, amides and esters under mild condition is described. This reaction is applicable to challenging couplings of hindered carboxylic acid with low nucleophilic amine or alcohol, giving products in good yields (67-90\%) without any racemization. This system employs highly reactive intermediate $\mathrm{Ph}_{3} \mathrm{PCl}_{2}$ as activator of carboxylate, in a catalytic manner, and drive the reaction to complete in short reaction time (less than $10 \mathrm{~min}$ ). It has the advantages of good functional group tolerance, broad substrate scope and good atom-economy. A $100 \mathrm{mmol}$ scale reaction with good yield shed light on its potential for industrial application. A plausible mechanism is proposed based on ${ }^{31} \mathrm{P}$ NMR monitor of reaction process.
}

Amide bond and ester bond formations are the most common reactions for the synthesis of pharmaceutical compounds and other organic transformations. ${ }^{1}$ Due to the significant utilities of such structural motifs, the synthesis of amides and esters has become one of the hottest research areas in both academia and industry. ${ }^{2}$ Early strategy to form amide and ester bonds is conversion of carboxylic acid moiety to a more reactive acyl halide (Scheme 1, eq a), which requires the harsh reagents such as $\mathrm{SOCl}_{2}, \mathrm{POCl}_{3},(\mathrm{COCl})_{2} \cdot{ }^{3}$ In addition, this strategy brings potential racemization of $\alpha$-chiral carboxylic acids. To mitigate these issues, coupling reagent strategy was developed for amide bond or ester bond formations (Scheme 1, eq b) ${ }^{3,4}$ Numerous coupling reagents have been developed, such as carbodiimides ${ }^{5}$, phosphoniums $^{6}$, uronium salts ${ }^{7}$, immoniums $^{8}$, imidazolium salts ${ }^{9}$ and pyridinium reagents ${ }^{10}$. Because of easy to handle, commercial reagents such as DCC, EDC, BOP, HATU are widely used in the activation of carboxylic acids. Meanwhile, novel types of activating strategies and coupling reagent systems have also been developed over the past few years, including ynamide-mediated esterification and amidation ${ }^{11}$, 2,4-bis(trifluoromethyl)phenylboronic acid catalyzed dehydrative condensation ${ }^{12}$, TCFH-NMI as coupling reagent $^{13}$, aminosilane-catalyzed amidation ${ }^{14}$, visible light and DMAP/CCl 3 Br assisted peptide coupling ${ }^{15}$. Unfortunately, preparation protocols of these coupling reagents involve harsh conditions and toxic reagents and it is not trivial to recycle 
these coupling reagents. The formation of amide bond and ester bond avoiding poor atom economy reagents is recognized as one of the top challenges in synthetic chemistry. ${ }^{1 \mathrm{~b}}$ In accordance with the principles of atom economy and step economy, coupling reagent with a high efficacy and low molecular weight while being environmentally friendly and practical is essential for the green future of esterification and amidation. ${ }^{16}$

Scheme 1. Recent progresses in amidation and esterification reactions

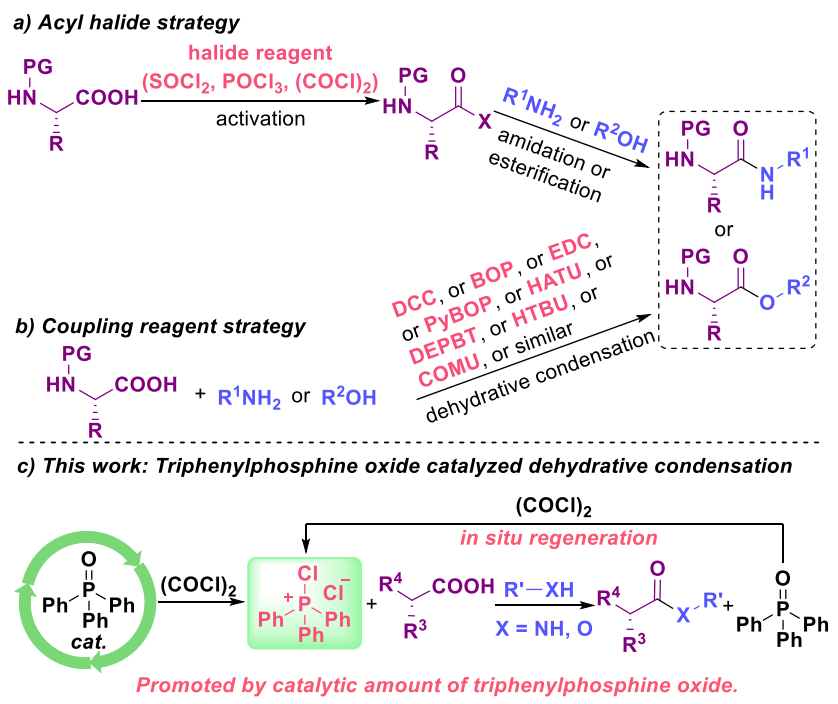

In seeking for new coupling system, we noticed that triphenylphosphine $\left(\mathrm{Ph}_{3} \mathrm{P}\right)$ is a versatile reagent. It was not only used in Wittig reaction ${ }^{17}$, Mitsunobu reaction ${ }^{18}$, Appel reaction $^{19}$ and Staudinger reaction ${ }^{20}$, but also in amide and peptide synthesis in which the stoichiometric intermediate chlorophosphonium salt $\left(\mathrm{Ph}_{3} \mathrm{PCl}^{+} / \mathrm{Cl}^{-}\right)$generated from triphenylphosphine and $\mathrm{CCl}_{4}$ (or $\mathrm{C}_{2} \mathrm{Cl}_{6}$ ) can efficiently activate carboxylate group, and stoichiometric amount of triphenylphosphine oxide $\left(\mathrm{Ph}_{3} \mathrm{PO}\right)$ was produced as intractable chemical waste. In order to apply $\mathrm{Ph}_{3} \mathrm{PCl}^{+} / \mathrm{Cl}^{-}$species in a more cost-effective and easy-to-handle way, several studies adopt the cheaper $\mathrm{Ph}_{3} \mathrm{PO} /$ oxalyl chloride $\left((\mathrm{COCl})_{2}\right)$ system for in situ formation of $\mathrm{Ph}_{3} \mathrm{PCl}^{+} / \mathrm{Cl}^{-}$. It is worth mentioning that early in 1977 Masaki and Fukui ${ }^{21}$ reported that the industrial byproduct $\mathrm{Ph}_{3} \mathrm{PO}$ could be easily converted into $\mathrm{Ph}_{3} \mathrm{PCl}^{+} / \mathrm{Cl}^{-}$, which was later applied in amide and ester synthesis via stoichiometric activation of non-chiral carboxylic acid ${ }^{22}$, amide to nitrile dehydration ${ }^{23}$, Appel reaction ${ }^{24}$ and others ${ }^{25}$. Through analysis of an improved Appel reaction where catalytic $\mathrm{Ph}_{3} \mathrm{PO}$ was continuously deoxygenated to the phosphonium $\mathrm{Ph}_{3} \mathrm{PCl}^{+} / \mathrm{Cl}^{-}$by $(\mathrm{COCl})_{2}{ }^{24 \mathrm{a}}$, and combined with the fact that phosphonium (e.g. BOP, PyBOP) are excellent coupling reagents in racemization-free activation of carboxylic acids, we hypothesized that $\mathrm{Ph}_{3} \mathrm{PO}($ cat. $) /(\mathrm{COCl})_{2}$ system generated $\mathrm{Ph}_{3} \mathrm{PCl}^{+} / \mathrm{Cl}^{-}$could also be applied to $\alpha$-chiral carboxylate activation and thus drives amide or ester bond formation. Herein, we reported an effective racemization-free amidation and esterification reaction of chiral carboxylic acids promoted by $\mathrm{Ph}_{3} \mathrm{PO}$ (cat.)/(COCl $)_{2}$ system (Scheme 1 , eq c).

Before screening the reaction conditions, we first compared the activating rates of carboxylic acid by $(\mathrm{COCl})_{2}$ with and without presence of $\mathrm{Ph}_{3} \mathrm{PO}$. To facilitate assignment of acti- vated species by ${ }^{31} \mathrm{P}$ NMR, model reactant alanine was $\mathrm{N}$ protected by a phosphoryl moiety. In ${ }^{31} \mathrm{P}$ NMR spectra (see Fig $\mathrm{S} 1 \sim \mathrm{S} 3)$, we found that $(\mathrm{COCl})_{2}$ alone can only slowly converts $\mathrm{N}$-protected alanine into corresponding acyl chloride, while $(\mathrm{COCl})_{2}$ and $\mathrm{Ph}_{3} \mathrm{PO}$ combined instantly and predominantly converts the reactant to phosphonium adduct (Scheme 2).

\section{Scheme 2. Activation of N-protected alanine by $(\mathrm{COCl})_{2}$ and $\mathrm{Ph}_{3} \mathrm{PO}$}

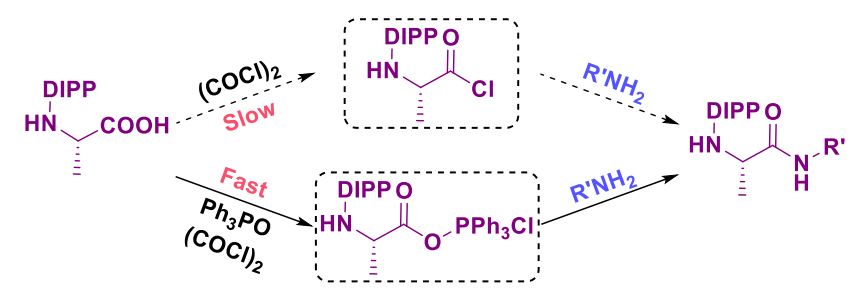

The investigation commenced with reaction conditions screening, the model reaction of $\mathrm{N}$-protected amino acid $\mathbf{1 a}$ and amino acid ester $\mathbf{2 a}$ was initially evaluated (Table 1). Using stoichiometric quantity of $\mathrm{Ph}_{3} \mathrm{PO} \mathbf{4 a}$ and 1.5 equiv of oxalyl chloride, dipeptide $\mathbf{3 a}$ was formed in moderate yield $(51 \%)$ with excellent diastereomeric purity (>99:1 dr) (Table 1, entry 1). Reduction of $\mathrm{Ph}_{3} \mathrm{PO} \mathbf{4 a}$ to $20 \mathrm{~mol} \%$ only resulted in a slightly lower yield (48\%) (Table 1, entry 2). These results prove that catalytic amount of $\mathrm{Ph}_{3} \mathrm{PO}$ is sufficed to accomplish the reaction. A series of solvents including toluene, tetrahydrofuran, 1,4-dioxane, acetonitrile, 1,2-dichloroethane, and dichloromethane were evaluated (Table 1, entries 3-7). It turns out that 1,2-dichloroethane was the favorite solvent and gave the dipeptide $\mathbf{3 a}$ in $83 \%$ yield without racemization. It should be noted that this reaction completed in less than $10 \mathrm{~min}$. Various phosphine oxides including triethyl phosphate $\mathbf{4 b}$, tricyclohexylphosphine oxide $\mathbf{4 c}$, hexamethylphosphoramide 4d, and tris(pyrrolidinophosphine) oxide $\mathbf{4 e}$ were briefly assessed and proved to be inferior (Table 1, entries 8-11). Replacement of oxalyl chloride with triphosgene did not produce the dipeptide 3a (Table 1, entry 12). Further reduction of catalyst loading to $5 \mathrm{~mol} \%$, a significantly lower yield $(43 \%)$ was observed (Table 1, entry 13). In the absence of $\mathrm{Ph}_{3} \mathrm{PO}$, the dipeptide 3a was not obtained (Table 1, entry 14). Based on the above screening, the optimal reaction conditions were established as following: amino acids 1 (1.0 equiv.), amino acid esters 2 (1.2 equiv.) and triphenylphosphine oxide 4a $(20 \mathrm{~mol} \%)$ were well mixed in 1,2-dichloroethane, oxalyl chloride ( 1.5 equiv.) and triethylamine ( 2.0 equiv.) were added in sequence at ambient temperature under argon atmosphere, the reaction mixture was stirred at ambient temperature for 10 $\min$.

Table 1. Optimization of the peptide bond-forming reaction $^{a}$ 


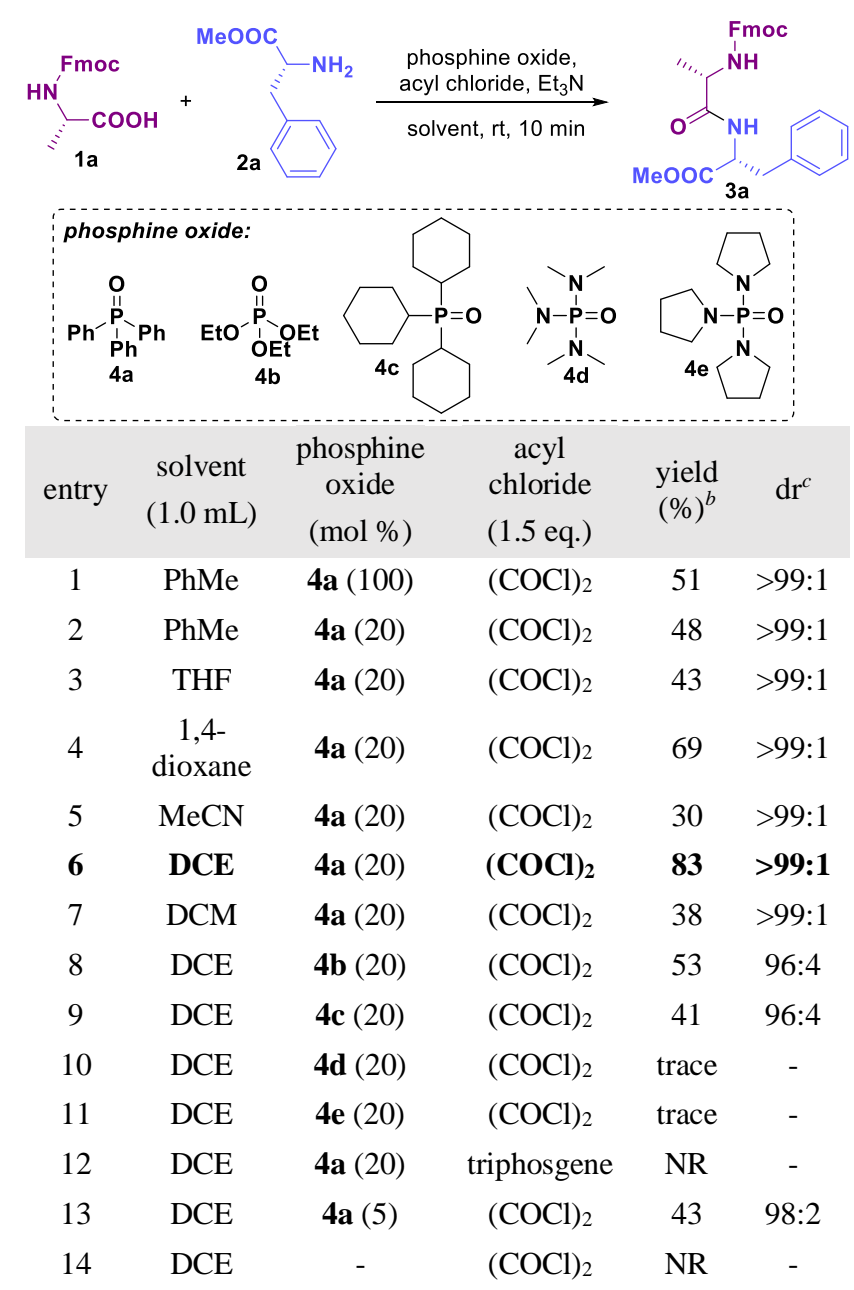

${ }^{a}$ Unless otherwise noted, all reactions were carried out using amino acid 1a (1.0 mmol, 1.0 equiv.), amino acid ester $\mathbf{2 a}(1.2$ mmol, 1.2 equiv.) and phosphine oxide 4 in solvent $(1.0 \mathrm{~mL})$ and acyl chloride ( $1.5 \mathrm{mmol}, 1.5$ equiv.) and triethylamine $(2.0 \mathrm{mmol}$, 2.0 equiv.) were added in sequence at ambient temperature in argon. ${ }^{b}$ Isolated yield. ${ }^{c}$ Determined by HPLC on a chiral stationary phase.

Having the optimal conditions in hand, we sought to examine the substrate tolerance for dipeptide synthesis (Scheme 3). It is found that common amine protecting groups such as Boc, $\mathrm{Cbz}$, and Fmoc could be tolerated (3a-3c). Different protecting groups had no noticeable influence on reaction yields (77$83 \%,>99: 1 \mathrm{dr}$ ). Coupling reactions between secondary amine L-proline ester and $N$-Fmoc-L-Ala also provided the corresponding dipeptide 3d in good yield (83\%, >99:1 dr). Reactions between several of amino acid tert-butyl esters and a series of $N$-Fmoc amino acids provided the corresponding dipeptides $\mathbf{3 e - 3 j}$ in good yields (84-88\%). Notably, side-chain protected amino acids (Ser, Cys, Asp) also reacted smoothly to give the corresponding dipeptides in good yields without racemization.

Scheme 3. Dipeptide synthesis ${ }^{a}$

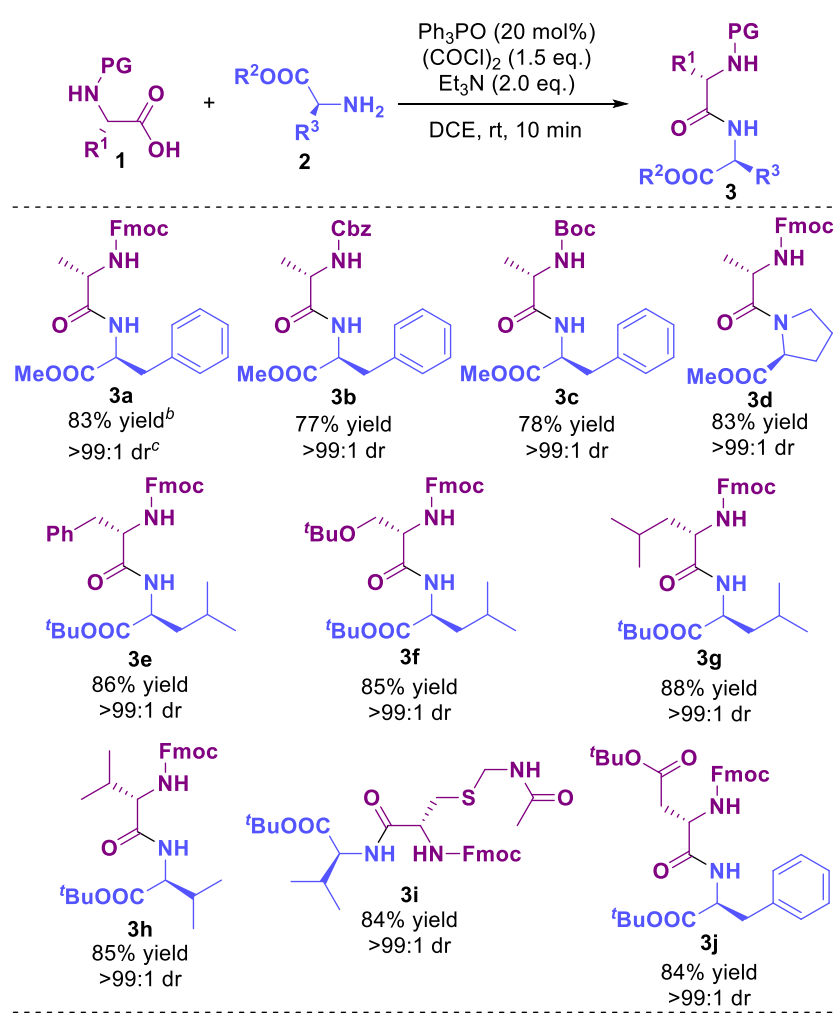

${ }^{a}$ Unless otherwise noted, all reactions were carried out using amino acids 1 (1.0 mmol, 1.0 equiv.), amino acid esters 2 (1.2 mmol, 1.2 equiv.) and triphenylphosphine oxide $4 \mathbf{a}$ in 1,2dichloroethane $(1.0 \mathrm{~mL})$ and oxalyl chloride $(1.5 \mathrm{mmol}, 1.5$ equiv.) and triethylamine ( $2.0 \mathrm{mmol}, 2.0$ equiv.) were added in sequence at ambient temperature in argon. ${ }^{b}$ Isolated yield. ${ }^{c}$ Determined by HPLC on a chiral stationary phase.

To test the reactivity of hindered carboxylic acid and low nucleophilic amine, 2-phenylisobutyric acid 5a and 4aminophthalonitrile 6a were investigated. This challenging coupling gives moderate yield (7a, 67\%). In addition, coupling reactions between ( $\mathrm{S}$ )-phenylpropionic acid and a series of amines bearing both electron-donating and -withdrawing substituents, including pyridine and pyrimidine, gave the corresponding amides $\mathbf{7 b - 7 h}$ in good yields (80-89\%) without racemization (Scheme 4).

\section{Scheme 4. Amide bond formation ${ }^{a}$}




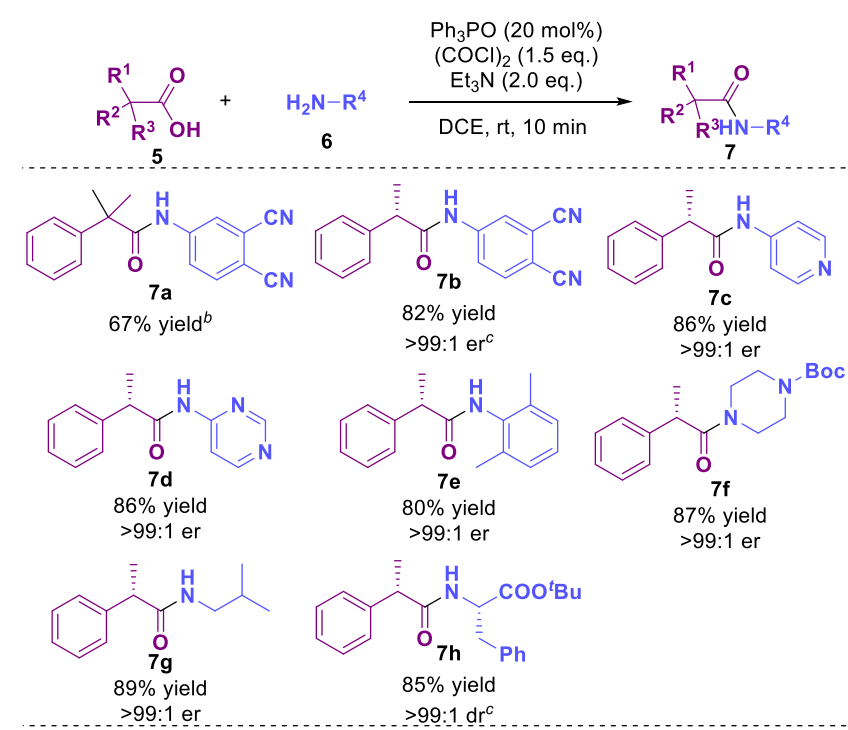

${ }^{a}$ Unless otherwise noted, all reactions were carried out using carboxylic acids 5 (1.0 mmol, 1.0 equiv.), amines 6 (1.2 mmol, 1.2 equiv.) and triphenylphosphine oxide 4a in 1,2-dichloroethane $(1.0 \mathrm{~mL})$ and oxalyl chloride $(1.5 \mathrm{mmol}, 1.5$ equiv.) and triethylamine ( $2.0 \mathrm{mmol}, 2.0$ equiv.) were added in sequence at ambient temperature in argon. ${ }^{b}$ Isolated yield. ${ }^{c}$ Determined by HPLC on a chiral stationary phase.

We next examined the coupling of $\mathrm{N}$-protected amino acid $\mathbf{8}$ and alcohol 9 components under our optimal conditions. As shown in scheme 5, the esterification of $\mathrm{N}$-Fmoc-L-Ala or $\mathrm{N}$ Fmoc-L-Phe with various alcohols including phenols and aliphatic alcohols bearing both electron-donating and withdrawing substituents proceeded smoothly to furnish the target esters 10a-10j in good yields $(79-90 \%,>99: 1 \mathrm{er})$.

\section{Scheme 5. Ester bond formation ${ }^{a}$}

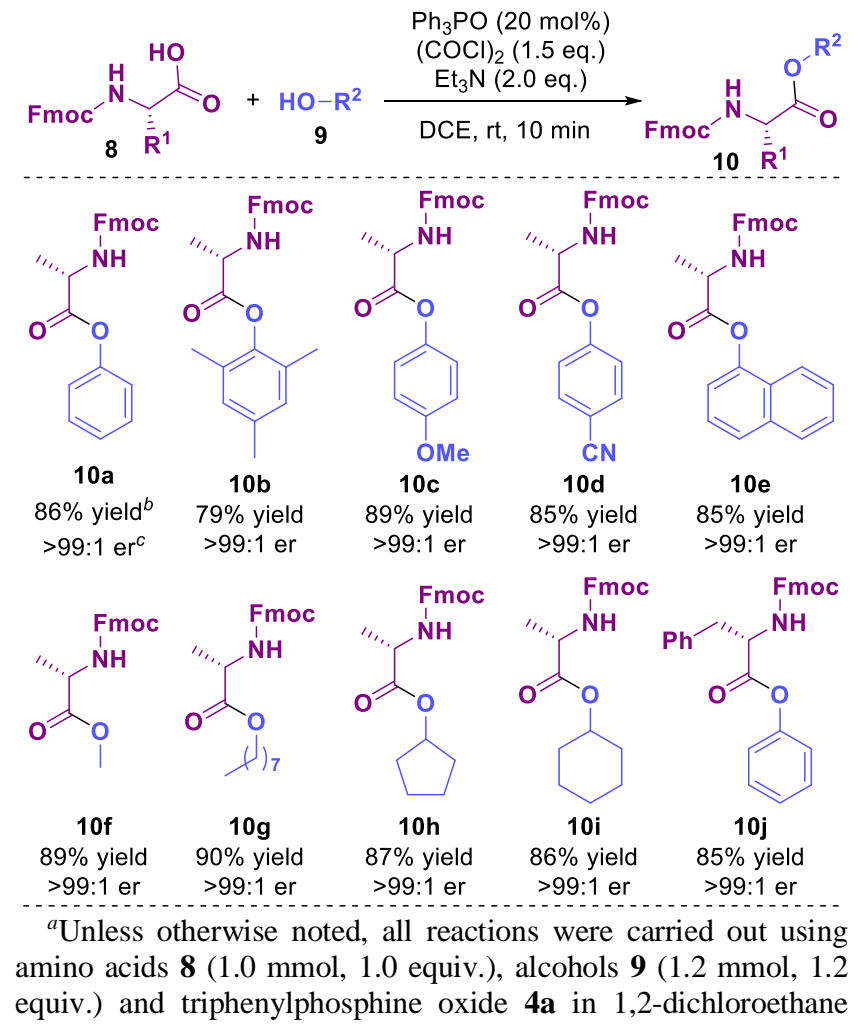

(1.0 mL) and oxalyl chloride ( $1.5 \mathrm{mmol}, 1.5$ equiv.) and triethylamine ( $2.0 \mathrm{mmol}, 2.0$ equiv.) were added in sequence at ambient temperature in argon. ${ }^{b}$ Isolated yield. ${ }^{c}$ Determined by HPLC on a chiral stationary phase.

To test the scalability of this protocol, synthesis of $\mathbf{3 a}$ at 100 mmol scale was carried out under the optimal reaction conditions. It gives isolated yield of $73 \%$ from simple recrystallization of product in dichloromethane, avoiding column chromatography (Scheme 6). Therefore, our protocol has potential value in industrial production of dipeptide.

\section{Scheme 6. $100 \mathrm{mmol}$ scale model reaction}

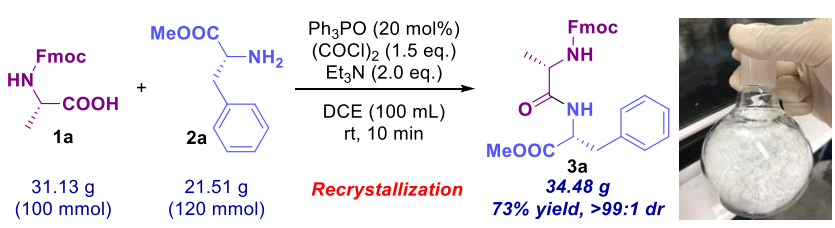

In order to elucidate the role of $\mathrm{Ph}_{3} \mathrm{PO}$ and $(\mathrm{COCl})_{2}$ and understand the nature of the catalytic cycle involved, ${ }^{31} \mathrm{P}$ NMR spectroscopy was used to monitor the reaction process. Based on the experimental results, a possible mechanism was proposed in Scheme 7. Initially, the solution of $\mathrm{Ph}_{3} \mathrm{PO}$ in DCE showed a strong singlet at $26.2 \mathrm{ppm}$ (Figure 1, a). A new signal appearance at $62.3 \mathrm{ppm}$ after addition of oxalyl chloride (Figure 1, b), indicating triphenylphosphine oxide reacted with oxalyl chloride to generate chlorophosphonium $\mathbf{A} .^{22,23,25 \mathrm{~d}}$ Then the in situ generated intermediate $\mathbf{A}$ serves as activator of the carboxylic acid. 1a converted it to a new resonance at 65.3 ppm (Figure 1, c), which is consistent with an acyl phosphonium salt $\mathbf{B} .^{22}$ Finally, the addition of amino acid ester $\mathbf{2 a}$ recovered a singlet at $26.2 \mathrm{ppm}$, the catalyst $\mathrm{Ph}_{3} \mathrm{PO}$ (Figure 1, d). It is worthy to mention that, the singlet at about $26.2 \mathrm{ppm}$ was mis-assigned to $\mathbf{C}$ or $\mathbf{D}$ in previous report. ${ }^{22}$ Actually, $\mathbf{C}$ or $\mathbf{D}$ are transient intermediates that is impossible to accumulate at present of nucleophiles such as amines and alcohols.

Scheme 7. Proposed mechanism of amidation and esterification mediated by $\mathrm{Ph}_{3} \mathrm{PO}$ and $(\mathrm{COCl})_{2}$

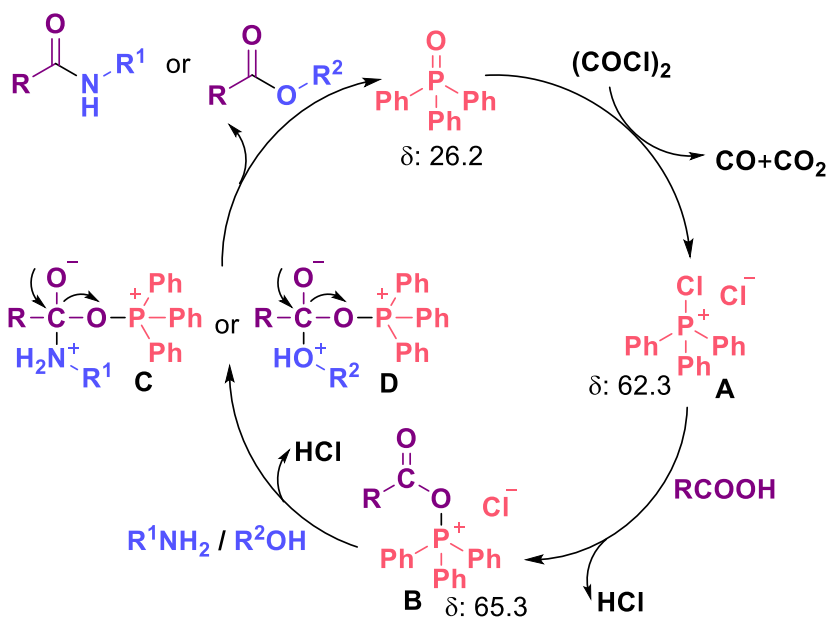




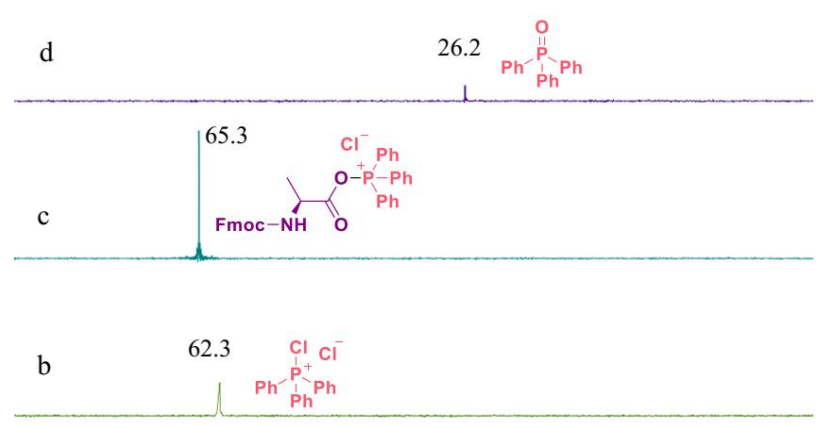

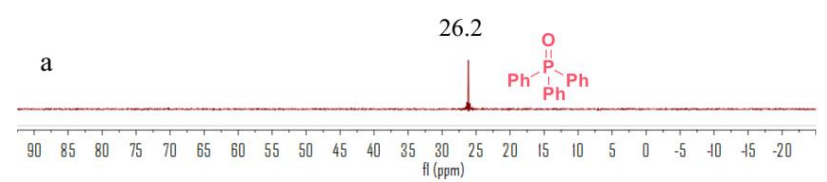

Figure 1. Monitored by ${ }^{31} \mathrm{P}$ NMR spectroscopy for synthesis dipeptide 3a. a: the solution of $\mathrm{Ph}_{3} \mathrm{PO}(0.2 \mathrm{mmol}, 20 \mathrm{~mol} \%)$ in DCE $(1.0 \mathrm{~mL})$. b: after addition of oxalyl chloride $(1.5 \mathrm{mmol}, 1.5$ equiv.) to 1 . c: amino acid $1 \mathbf{a}(1.0 \mathrm{mmol}, 1.0$ equiv.) added to 2 . d: amino acid ester $\mathbf{2 a}$ ( $1.2 \mathrm{mmol}, 1.2$ equiv.) and triethylamine (2.0 mmol, 2.0 equiv.) were added to solution of 3 .

In summary, we successfully developed an effective amidation and esterification reaction for $\alpha$-chiral carboxylic acids. This reaction system employs catalytic amount of triphenylphosphine oxide and stoichiometric amount of oxalyl chloride under mild condition to in situ forming highly active and efficient phosphonium intermediate $\mathrm{Ph}_{3} \mathrm{PCl}_{2}$, which can drive even challenging couplings of hindered carboxylic acids and low nucleophilic amines or alcohols. The reaction is easy to operate and is able to synthesize dipeptides, amides and esters in good yields (67-90\%) without racemization. Our system has the advantages of short reaction time (less than 10 min), using cheap and readily available reagents, good functionals tolerance, broad substrate scope and atom-economy (only $\mathrm{CO}, \mathrm{CO}_{2}$ and $\mathrm{HCl}$ as wastes in the end of reaction). A 100 mmol-scale reaction was successfully realized, showing its potential for industrial application.

\section{ASSOCIATED CONTENT}

\section{Supporting Information}

Complete experimental procedures and characterization of new products; NMR spectra and HPLC chromatograms (PDF)

\section{AUTHOR INFORMATION}

\section{Corresponding Author}

Feng Ni - Institute of Drug Discovery Technology; Qian Xuesen Collaborative Research Center of Astrochemistry and Space Life Sciences, Ningbo University, Ningbo, Zhejiang, 315211, P. R. China; orcid.org/0000-0001-8482-6755; E-mail: nifeng@nbu.edu.cn

\section{Authors \\ Ji-Wei Ren - Institute of Drug Discovery Technology; Qian Xuesen Collaborative Research Center of Astrochemistry and Space Life Sciences, Ningbo University, Ningbo, Zhejiang, 315211, P. R. China; orcid.org/0000-0001-5796-4976 Meng-Nan Tong - Institute of Drug Discovery Technology, Ningbo University, Ningbo, Zhejiang, 315211, P. R. China Yu-Fen Zhao - Institute of Drug Discovery Technology; Qian Xuesen Collaborative Research Center of Astrochemistry and}

Space Life Sciences, Ningbo University, Ningbo, Zhejiang, 315211, P. R. China

\section{Notes}

The authors declare no competing financial interest.

\section{ACKNOWLEDGMENT}

We gratefully acknowledge the financial support from the Scientific Research Grant of Ningbo University (215-432000282), Ningbo Top Talent Project (215-432094250), Natural Science Foundation of Ningbo (202003N4093) and Ningbo University.

\section{REFERENCES}

(1) (a) Roughley, S. D.; Jordan, A. M. The medicinal chemist's toolbox: An analysis of reactions used in the pursuit of drug candidates. J. Med. Chem. 2011, 54, 3451-3479. (b) Constable, D. J. C.; Dunn, P. J.; Hayler, J. D.; Humphrey, G. R.; Leazer, J. J. L.; Linderman, R. J.; Lorenz, K.; Manley, J.; Pearlman, B. A.; Wells, A.; Zaks, A.; Zhang, T. Y. Key green chemistry research areas: A perspective from pharmaceutical manufacturers. Green Chem. 2007, 9, 411-420. (c) Brown, D. G.; Bostrom, J. Analysis of past and present synthetic methodologies on medicinal chemistry: Where have all the new reactions gone? J. Med. Chem. 2016, 59, 4443-4458. (d) Uhlig, T.; Kyprianou, T.; Martinelli, F. G.; Oppici, C. A.; Heiligers, D.; Hills, D.; Calvo, X. R.; Verhaert, P. The emergence of peptides in the pharmaceutical business: From exploration to exploitation. EuPA Open Proteomics 2014, 4, 58-69. (e) Tani, K.; Stoltz, B. M. Synthesis and structural analysis of 2-quinuclidonium tetrafluoroborate. Nature 2006, 441, 731-734. (f) Sabatini, M. T.; Boulton, L. T.; Sneddon, H. F.; Sheppard, T. D. A green chemistry perspective on catalytic amide bond formation. Nature Catalysis 2019, 2, 10-17.

(2) Marchildon, K. Polyamides: Still strong after seventy years. Macromol. React. Eng. 2011, 5, 22-54.

(3) El-Faham, A.; Albericio, F. Peptide coupling reagents, more than a letter soup. Chem. Rev. 2011, 111, 6557-6602.

(4) (a) Sperry, J. B.; Minteer, C. J.; Tao, J.; Johnson, R.; Duzguner, R.; Hawksworth, M.; Oke, S.; Richardson, P. F.; Barnhart, R.; Bill, D. R.; Giusto, R. A.; Weaver, J. D. Thermal stability assessment of peptide coupling reagents commonly used in pharmaceutical manufacturing. Org. Process Res. Dev. 2018, 22, 1262-1275. (b) Albericio, F.; El-Faham, A. Choosing the right coupling reagent for peptides: A twenty-five-year journey. Org. Process Res. Dev. 2018, 22, 760-772.

(5) Sheehan, J. C.; Hess, G. P. A new method of forming peptide bonds. J. Am. Chem. Soc. 1955, 77, 1067-1068.

(6) Gawne, G.; Kenner, G. W.; Sheppard, R. C. Acyloxyphosphonium salts as acylating agents. Synthesis of peptides. J. Am. Chem. Soc. 1969, 91, 5669-5671.

(7) (a) Carpino, L. A.; El-Faham, A.; Albericio, F. Efficiency in peptide coupling: 1-Hydroxy-7-azabenzotriazole vs 3,4-dihydro-3hydroxy-4-oxo-1,2,3-benzotriazine. J. Org. Chem. 1995, 60, 35613564. (b) Carpino, L. A.; Henklein, P.; Foxman, B. M.; Abdelmoty, I.; Costisella, B.; Wray, V.; Domke, T.; El-Faham, A.; Mugge, C. The solid state and solution structure of HAPyU. J. Org. Chem. 2001, 66 , 5245-5247.

(8) (a) El-Faham, A.; Khattab, S. N.; Abdul-Ghani, M.; Albericio, F. Design and synthesis of a new immonium type coupling reagents. Eur. J. Org. Chem. 2006, 6, 1563-1573. (b) El-Faham, A.; Albericio, F. Novel proton acceptor immonium type coupling reagents: Application in solution and solid phase peptide synthesis. Org. Lett. 2007, 9, 4475-4477. (c) El-Faham, A.; Albericio, F. Morpholine-based immonium and halogenoamidinium salts as coupling reagents in peptide synthesis. J. Org. Chem. 2008, 73, 2731-2737.

(9) Akaji, K.; Kuriyama, N.; Kimura, T.; Fujiwara, Y.; Kiso, Y. Anchoring of Fmoc amino acid to 4-alkoxybenzyl alcohol resin using a new esterification reagent. Tetrahedron Lett. 1992, 33, 3177-3180.

(10) Li, P.; Xu, J. C. BOMI-A novel peptide coupling reagent. Tetrahedron Lett. 1999, 40, 3605-3608.

(11) (a) Yang, M.; Wang, X.; Zhao, J. Ynamide-mediated macrolactonization. ACS Catal. 2020, 10, 5230-5235. (b) Wang, X.; Yang, 
Y.; Zhao, Y.; Wang, S.; Hu, W.; Li, J.; Wang, Z.; Yang, F.; Zhao, J. Ynamide-mediated intermolecular esterification. J. Org. Chem. 2020, 85, 6188-6194. (c) Hu, L.; Xu, S.; Zhao, Z.; Yang, Y.; Peng, Z.; Yang, M.; Wang, C.; Zhao, J. Ynamides as racemization-free coupling reagents for amide and peptide synthesis. J. Am. Chem. Soc. 2016, 138, $13135-13138$.

(12) Wang, K.; Lu, Y.; Ishihara, K. The ortho-substituent on 2,4bis(trifluoromethyl)phenylboronic acid catalyzed dehydrative condensation between carboxylic acids and amines. Chem. Commun. 2018, $54,5410-5413$.

(13) Beutner, G. L.; Young, I. S.; Davies, M. L.; Hickey, M. R.; Park, H.; Stevens, J. M.; Ye, Q. TCFH-NMI: Direct access to N-acyl imidazoliums for challenging amide bond formations. Org. Lett. 2018, 20, 4218-4222.

(14) Muramatsu, W.; Manthena, C.; Nakashima, E.; Yamamoto, H. Peptide bond-forming reaction via amino acid silyl esters: New catalytic reactivity of an aminosilane. ACS Catal. 2020, 10, 9594-9603.

(15) Mishra, A. K.; Parvari, G.; Santra, S. K.; Bazylevich, A.; Dorfman, O.; Rahamim, J.; Eichen, Y.; Szpilman, A. M. Solar and visible light assisted peptide coupling. Angew. Chem., Int. Ed. 2021, 60, 12406-12412.

(16) (a) Kamiński, Z. J.; Kolesińska, B.; Kolesińska, J.; Sabatino, G.; Chelli, M.; Rovero, P.; Błaszczyk, M.; Głowka, M. L.; Papini, A. M. N-Triazinylammonium tetrafluoroborates. A new generation of efficient coupling reagents useful for peptide synthesis. J. Am. Chem. Soc. 2005, 127, 16912-16920. (b) Krause, T.; Baader, S.; Erb, B.; Gooßen, L. J. Atom-economic catalytic amide synthesis from amines and carboxylic acids activated in situ with acetylenes. Nat. Commun. 2016, 7, 11732-11738. (c) Tian, J.; Gao, W.-C.; Zhou, D.-M.; Zhang, C. Recyclable hypervalent iodine(III) reagent iodosodilactone as an efficient coupling reagent for direct esterification, amidation, and peptide coupling. Org. Lett. 2012, 14, 3020-3023. (d) Orliac, A.; Gomez Pardo, D.; Bombrun, A.; Cossy, J. XtalFluor-E, an efficient coupling reagent for amidation of carboxylic Acids. Org. Lett. 2013 15, 902-905. (e) Subiros-Funosas, R.; Prohens, R.; Barbas, R.; ElFaham, A.; Albericio, F. Oxyma: An efficient additive for peptide synthesis to replace the benzotriazole-based HOBt and HOAt with a lower risk of explosion. Chem. Eur. J. 2009, 15, 9394-9403.

(17) (a) Eggersdorfer, M.; Laudert, D.; Létinois, U.; McClymont, T.; Medlock, J.; Netscher, T.; Bonrath, W. One hundred years of vitamins-A success story of the natural sciences. Angew. Chem., Int. Ed. 2012, 51, 12960-12990. (b) van Kalkeren, H. A.; Blom, A. L.; Rutjes, F. P. J. T.; Huijbregts, M. A. J. On the usefulness of life cycle assessment in early chemical methodology development: The case of organophosphorus-catalyzed Appel and Wittig reactions. Green Chem. 2013, 15, 1255-1263. (c) O'Brien, C. J.; Tellez, J. L.; Nixon, Z. S.; Kang, L. J.; Carter, A. L.; Kunkel, S. R.; Przeworski, K. C.; Chass, G.
A. Recycling the waste: The development of a catalytic wittig reaction. Angew. Chem., Int. Ed. 2009, 48, 6836-6839.

(18) Fletcher, S. The Mitsunobu reaction in the 21 St century. Org. Chem. Front. 2015, 2, 739-752.

(19) van Kalkeren, H. A.; Leenders, S. H.; Hommersom, C. R.; Rutjes, F. P.; van Delft, F. L. In situ phosphine oxide reduction: A catalytic Appel reaction. Chem. Eur. J. 2011, 17, 11290-11295.

(20) van Kalkeren, H. A.; Bruins, J. J.; Rutjes, F. P. J. T.; van Delft, F. L. Organophosphorus-catalysed Staudinger reduction. Adv. Synth. Catal. 2012, 354, 1417-1421.

(21) Masaki M, Fukui K. Reaction of tertiary phosphine dichlorides with thiols in the presence of triethylamine. A convenient method for the reduction of phosphine oxides to phosphines. Chem. Lett. 1977, 6, 151-152.

(22) (a) Jiang, L.; Yu, J.; Niu, F.; Zhang, D.; Sun, X. A highefficient method for the amidation of carboxylic acids promoted by triphenylphosphine oxide and oxalyl chloride. Heteroatom Chemistry 2017, 28, https://doi.org/10.1002/hc.21364. (b) Jia, M.; Jiang, L.; Niu, F.; Zhang, Y.; Sun, X. A novel and highly efficient esterification process using triphenylphosphine oxide with oxalyl chloride. $R$. Soc. Open Sci. 2018, 5, 171988-171999.

(23) Shipilovskikh, S. A.; Vaganov, V. Y.; Denisova, E. I.; Rubtsov, A. E.; Malkov, A. V. Dehydration of amides to nitriles under conditions of a catalytic appel reaction. Org. Lett. 2018, 20, 728731.

(24) (a) Denton, R. M.; An, J.; Adeniran, B.; Blake, A. J.; Lewis, W.; Poulton, A. M. Catalytic phosphorus(V)-mediated nucleophilic substitution reactions: Development of a catalytic Appel reaction. $J$. Org. Chem. 2011, 76, 6749-6767. (b) Denton, R. M.; An, J.; Adeniran, B. Phosphine oxide-catalysed chlorination reactions of alcohols under Appel conditions. Chem. Commun. 2010, 46, 3025-3027. (c) Byrne, P. A.; Rajendran, K. V.; Muldoon, J.; Gilheany, D. G. A convenient and mild chromatography-free method for the purification of the products of Wittig and Appel reactions. Org. Biomol. Chem. 2012, 10, 35313537.

(25) (a) Zhu, H.; Qu, Z. W.; Grimme, S. Reduction of phosphine oxide by using chlorination reagents and dihydrogen: DFT Mechanistic insights. Chem. Eur. J. 2019, 25, 4670-4672. (b) Yu, T. Y.; Wang, Y.;Xu, P. F. An unusual triphenylphosphine oxide catalyzed stereoselective 1,3-dichlorination of unsaturated ketoesters. Chem. Eur. J. 2014, 20, 98-101. (c) Kapusniak, L.; Plessow, P. N.; Trzybinski, D.; Wozniak, K.; Hofmann, P.; Jolly, P. I. A mild one-pot reduction of phosphine(V) oxides affording phosphines(III) and their metal catalysts. Organometallics 2021, 40, 693-701. (d) Bornemann, D.; Pitts, C. R.; Wettstein, L.; Bruning, F.; Kung, S.; Guan, L.; Trapp, N.; Grutzmacher, H.; Togni, A. Deoxygenative fluorination of phosphine oxides: A general route to fluorinated organophosphorus(V) compounds and beyond. Angew. Chem., Int. Ed. 2020, 59, 22790-22795. 